\title{
Soy Protein Isolate Films Incorporated with Pinhão (Araucaria angustifolia (Bertol.) Kuntze) Extract for Potential Use as Edible Oil Active Packaging
}

\author{
Karen Cristine de Souza ${ }^{1}$ - Luana Gabrielle Correa ${ }^{2} \cdot$ Tamires Barlati Vieira da Silva $^{3}$. \\ Thaysa Fernandes Moya Moreira ${ }^{3} \cdot$ Anielle de Oliveira $^{3} \cdot$ Lyssa Setsuko Sakanaka ${ }^{3}$ Maria Inês Dias ${ }^{4} \cdot$ Lillian Barros $^{4}$. \\ Isabel C.F.R. Ferreira ${ }^{4}$ (D) Patrícia Valderrama ${ }^{3} \cdot$ Fernanda Vitória Leimann $^{3}$ (D) $\cdot$ Marianne Ayumi Shirai $^{1}$ (D)
}

Received: 31 January 2020 / Accepted: 23 April 2020 / Published online: 12 May 2020

(C) Springer Science+Business Media, LLC, part of Springer Nature 2020

\begin{abstract}
One of the traditional residues obtained from pinhão seeds (Araucaria angustifolia (Bertol.) Kuntze) consists of an aqueous extract produced from the cooking process, which presents a significant concentration of phenolic compounds with antioxidant properties. In this work, soy protein isolate (SPI) films with different concentrations of pinhão cooking water extract (EP, $0.5,1$, and $2 \% \mathrm{wt} / \mathrm{wt}$ ) were produced and physical properties, microstructure, and antioxidant capacity were investigated. The films were applied as packaging (as sachet-type) for linseed oil, and the oil oxidative stability was evaluated during 10 days under accelerated storage condition $\left(60^{\circ} \mathrm{C}\right)$ by conventional procedures (peroxide index, specific extinction coefficient, and UV-Vis spectrophotometry) and by multivariate curve resolution with alternating least squares (MCR-ALS) chemometric method. The film with EP contributed to the oxidative stability of linseed oil being an interesting alternative of active biodegradable packaging for edible oils.
\end{abstract}

Keywords Pinhão seed coats $\cdot$ Biopolymers $\cdot$ Active packaging $\cdot$ Antioxidant capacity $\cdot$ Lipid oxidation $\cdot$ Chemometrics

Isabel C.F.R. Ferreira

iferreira@ipb.pt

$\triangle$ Fernanda Vitória Leimann

fernandaleimann@utfpr.edu.br

$\triangle$ Marianne Ayumi Shirai

marianneshirai@utfpr.edu.br

1 Programa de Pós-Graduação em Tecnologia de Alimentos (PPGTAL), Universidade Tecnológica Federal do Paraná, Campus Londrina, Avenida dos Pioneiros, 3131,

Londrina, Paraná 86036-370, Brazil

2 Departamento Acadêmico de Alimentos (DAALM), Universidade Tecnológica Federal do Paraná, Campus Londrina, Avenida dos Pioneiros, 3131, Londrina, Paraná 86036-370, Brazil

3 Programa de Pós-Graduação em Tecnologia de Alimentos (PPGTA), Universidade Tecnológica Federal do Paraná, Campus Campo Mourão, via Rosalina Maria Dos Santos, 1233, Caixa Postal: 271, Campo Mourão, Paraná 87301-899, Brazil

4 Centro de Investigação de Montanha (CIMO), Instituto Politécnico de Bragança, Campus de Santa Apolónia,

5300-253 Bragança, Portugal

\section{Introduction}

Protein-based films have aroused great interest in the production of packages because they have good oxygen barrier property, resistance to oils, and biodegradability (Insaward et al. 2015). Among the plant origin proteins, soy protein isolate (SPI), a by-product of oil processing industry, is an interesting raw material because of its abundance and high protein content $(>90 \%)$ (Cao et al. 2007). SPI is a mixture of proteins which contain approximately $90 \%$ globulins, and the major fractions are 7S ( $\beta$-conglicinin) and 11S (glycine) (Kumar et al. 2010). Heat and $\mathrm{pH}$ assist in the formation of the SPIbased film due to the denaturation of the protein structure, cleaving native disulfide bonds and exposing sulfhydryl groups and hydrophobic groups, and thus, new bonds between the protein chains are formed during drying of the film (PerezGago et al. 1999).

Due to its properties, SPI films can be a promising matrix for the incorporation of bioactive compounds in order to obtain active packaging with antioxidant and antimicrobial properties. The incorporation of natural antioxidants extracted from different parts of plants into packaging materials is 
interesting because oxidation is one of the major problems that affect food quality (Siripatrawan and Noipha 2012). In addition, the food industry has been looking to minimize the use of synthetic antioxidants (butyl hydroxyanisole (BHA), butyl hydroxytoluene (BHT), tertiary butylhydroxyquinone (TBHQ), trihydroxybutylphenone (THBP), and propyl gallate (PG)), since toxicological studies have demonstrated the possibility of these antioxidants presenting some toxic effect (Neltner et al. 2013).

Different natural antioxidants have been extracted and incorporated into the SPI film formulation, such as rutin, epicatechin (Friesen et al. 2015), pink grape extract (Ciannamea et al. 2016), mango seed extract (Maryam Adilah et al. 2018), chestnut extract (Wang et al. 2016), and licorice residue extract (Han et al. 2018). Studies have shown that the pinhão coat extract (Araucaria angustifolia (Bertol.) Kuntze) has a considerable concentration of phenolic compounds that have antioxidant capacity (De Freitas et al. 2018; Santos et al. 2018), being an interesting compound to be added in the formulation of SPI films. Pinhão is the seed from Araucaria angustifolia (Bertol.) Kuntze, a conifer that develops in southern Brazil, Argentina, and Paraguay in native forests that today represent about $1 \%$ of the original area (Cordenunsi et al. 2004). Culturally, their seeds are eaten boiled and peeled, and their coats, as well as cooking water which are sources of antioxidants, are largely discarded as residue.

However, possible interactions that may arise among the various components of film formulation during its formation would affect the potential release or retention of active ingredients, thus affecting their final activity (Echeverría et al. 2016). According to Salgado et al. (2015), even the determination of a certain activity by an in vitro technique does not ensure that the container can gain the ability to protect the food during storage. Thus, it is important to evaluate its action in a situation closer to reality, such as an edible oil packaging application. In this sense, Carpiné et al. (2015) evaluated the applicability of SPI emulsion-based films for olive oil. However, the main objective of their work was to evaluate the effect of virgin coconut oil and soy lecithin incorporation to the films on the water vapor barrier properties. ColínChávez et al. (2014) studied the effect of coextruded twolayer high-density polyethylene (HDPE) active packaging containing marigold flower (Tagetes erecta) extract and titanium dioxide in the oxidative stability of the soybean oil. Although the packaging has improved the soybean oil stability, the polymer used is not biodegradable.

An interesting edible oil that can be applied to evaluate film active properties is the flaxseed oil. It is an excellent source of $\omega-3$ polyunsaturated fatty acid and contains more than $50 \%$ $\alpha$-linolenic acid (Bozan and Temelli 2008). However, the polyunsaturated fatty acids present in linseed oil are easily oxidized and can form active free radicals in the presence of heat, light, oxygen reactive species, metals, etc., which become hydroperoxides and secondary oxidation products such as aldehydes, ketones, and other high molecular weight polymers (Choe and Min 2006). The presence of such oxidation products may alter the physico-chemical properties of the oils and reduce their shelf life, nutritional value, texture, appearance, and flavor, and therefore, the oxidative stability of linseed oil must be improved for processing, handling, and storage (Mohanan et al. 2018). Thus, SPI films enriched with pinhão coat extract can be used in the production of antioxidant packages to aid in the conservation of linseed oil.

The aim of this work was to chemically characterize pinhão coat extract, perform its incorporation during SPI film production, and evaluate the physical, morphological, and total phenolic compound content and antioxidant capacity of the obtained materials. Also, films were applied as sachet-type packaging for linseed oil, and the shelf life was evaluated by conventional methods (peroxide index analysis and specific extinction coefficient), as well as by the multivariate curve resolution with alternating least squares (MCR-ALS) chemometric method.

\section{Material and Methods}

\section{Material}

To produce the films, soy protein isolate $(>90 \%$ protein, Bremil, Brazil) and glycerol (Synth, Brazil) were used. The pinhão seeds were acquired from the local market in Campo Mourão, Paraná, Brazil, in May 2017. For the analyses of total phenolic compounds, Folin-Ciocalteu reagent, gallic acid, and sodium carbonate were used. For the antioxidant activity, assay DPPH (2,2-diphenyl-1-picrylhydrazyl), Trolox (6-hydroxy-2,5,7,8-tetramethychroman-2-carboxylic acid), ABTS (2,2'-azinobis[3-ethylbenzothiazoline-6-sulfonic acid] diammonium salt), potassium persulfate (dipotassium peroxydisulfate), and TPTZ (2,4,6-Tris(2-pyridyl)-s-triazine) were used and purchased from Sigma-Aldrich.

\section{Pinhão Coat Extract Production}

The pinhão coat extract (EP) was obtained according to the procedure described by De Freitas et al. (2018). The pinhão seeds were washed with water and cooked in water for $2 \mathrm{~h}$ (500 $\mathrm{g}$ of seeds/L water). The cooking water was frozen ($90{ }^{\circ} \mathrm{C}$ ) and lyophilized (Liotop L101, Liobrás, Brazil) obtaining the dry extract of the cooking water of the pinhão (EP). 


\section{Phenolic Profile of Pinhão Coat Extract}

The phenolic profile of EP $(10 \mathrm{mg} / \mathrm{mL}$ in water $)$ was determined by HPLC-DAD-ESI/MSn (Dionex Ultimate 3000 UPLC, Thermo Scientific, San Jose, CA, USA). The compounds were separated and identified as previously described (Bessada et al. 2016). Detection was performed using a DAD (280, 330, and $370 \mathrm{~nm}$ as preferred wavelengths) and a mass spectrometer (MS detection was performed in negative mode, using a Linear Ion Trap LTQ XL, Thermo Finnigan, San Jose, CA, USA). The following calibration curves were used for quantification: $(+)$-catechin $\left(y=84,950 x-23,200, R^{2}=1\right)$; chlorogenic acid $\left(y=168,823 x-161,172, R^{2}=0.9999\right)$; (-)epicatechin $\left(y=10,314 x+147,331, R^{2}=0.9994\right)$; ferulic acid $\left(y=633,126 x-185,462, R^{2}=0.9990\right)$; naringenin $(y=$ $\left.18,433 x+78,903, R^{2}=0.9998\right)$; and protocatechuic acid $\left(y=214,168 x+27,102, R^{2}=0.9999\right)$. Results were expressed as milligrams per gram of extract.

\section{Production of SPI Films with Pinhão Coat Extract}

The SPI films were prepared by the casting method according Paglione et al. (2019). The formulations consisted of $7.56 \%$ $(\mathrm{wt} / \mathrm{wt}$ ) of SPI in relation to the film-forming solution and $25 \%(\mathrm{wt} / \mathrm{wt})$ of glycerol in relation to SPI. Firstly, SPI was solubilized in distilled water at $25^{\circ} \mathrm{C}$; subsequently, solution's $\mathrm{pH}$ was adjusted to $10.5(1 \mathrm{M}, \mathrm{NaOH})$ and kept under stirring for $30 \mathrm{~min}$. The film-forming solution was heated to $70{ }^{\circ} \mathrm{C}$ during $20 \mathrm{~min}$ and finally cooled to room temperature. The lyophilized EP was added to the film-forming solution $(0.5,1$, or $2 \%$ in relation to film-forming solution, wt $/ \mathrm{wt}$ ) and homogenized using Ultraturrax (IKA, T18 model, USA) at $10,000 \mathrm{rpm}$ for $3 \mathrm{~min}$. The concentration of the EP added in the film was obtained from our preliminary studies (unpublished) for good film. All the film-forming solutions were poured into acrylic plates and dried at $25{ }^{\circ} \mathrm{C}$ and $45 \%$ $\mathrm{RH}$ for $24 \mathrm{~h}$ in an incubator. After that, the films were peeled and stored in a desiccator at $25^{\circ} \mathrm{C}$ and $53 \% \mathrm{RH}$ for $48 \mathrm{~h}$ before the characterizations were performed. The samples were coded as C (control), EP0.5, EP1, and EP2, according on the amount of extract added.

\section{Film Characterization}

\section{Mechanical Properties and Water Vapor Permeability}

The tensile test was performed using a texturometer (Stable Micro Systems, TA-TX2 model, England) and the properties obtained were maximum tensile strength (MPa), elongation at break (\%), and modulus of elasticity or Young's modulus $(\mathrm{MPa})$ according to the methods and standards of the American Society for Testing and Material (ASTM D882$12,2012)$. The films $(100 \mathrm{~mm} \times 10 \mathrm{~mm})$ were fixed to the grips of the equipment with initial distance of $30 \mathrm{~mm}$ and crosshead speed of $0.8 \mathrm{~mm} / \mathrm{s}$. For each formulation, $10 \mathrm{sam}-$ ples were analyzed. The water vapor permeability was determined using the gravimetric method, according to the American Society for Testing and Material (ASTM E96E96M, 2012), using circular opening aluminum cell with a 60-mm internal diameter under a relative humidity gradient of $0-75 \%$. The assay was performed in triplicate.

\section{Color}

The color of the films was measured with a colorimeter (Konica Minolta, CR-400 model, Japan) using D65 illuminant. The samples were placed in direct contact with the sensor to measure the color parameters $L^{*}$ luminosity (black/ white), $a^{*}$ (green/red), and $b^{*}$ (blue/yellow). Ten random measurements were done for each formulation in aleatory points from the material surface. The color difference $(\Delta E)$ was calculated in relation to the control formulation with Eq. 1, where $\Delta L^{*}, \Delta a^{*}$, and $\Delta b^{*}$ are the differences between the film containing the EP and the control film:

$\Delta E=\sqrt{\left(\Delta L^{*}\right)^{2}+\left(\Delta a^{*}\right)^{2}+\left(\Delta b^{*}\right)^{2}}$

\section{Scanning Electron Microscopy}

The morphology of the films was evaluated by scanning electron microscopy. The samples were previously dried for 14 days in a desiccator containing silica gel and, later, fractured in liquid nitrogen and fixed on stubs with carbon tape. Then samples were covered with gold in a sputter coater (BAL-TEC, SCD-050, Balzers, Liechtenstein) and analyzed in relation to the surface and fragile fracture in a scanning electron microscope (Philips, FEI Quanta 200, Japan) at $20 \mathrm{kV}$. The magnifications applied to the fragile fracture and surface areas were $\times 800$ and $\times 400$, respectively.

\section{Infrared Spectroscopy with Fourier Transform}

The chemical interactions between the films and the pinhão coat extract were characterized by Fourier transform infrared spectroscopy attenuated total reflectance. The spectra were obtained in a Fourier transform infrared spectroscopy (FTIR) (IRAffinity, Shimadzu, Japan) spectrometer equipped with an attenuated total reflectance accessory (ZnSe crystal, Pike ATR-HATR flat plate). The samples were evaluated in the range of 700-4000 $\mathrm{cm}^{-1}$, using 32 accumulated scans and $2 \mathrm{~cm}^{-1}$ of resolution. To extract the antioxidant compounds from the films, $10 \mathrm{~mL}$ of distilled water was added to $0.5 \mathrm{~g}$ of film and homogenized for $1 \mathrm{~h}$ at room temperature using a tube shaker (Phoenix, Brazil). Subsequently, the mixture was 
centrifuged, and the supernatant was used to determine the total phenolic compounds (Folin-Ciocalteu method) and antioxidant activity by DPPH, ABTS, and FRAP methods. The extraction was performed in triplicate.

\section{Total Phenolic Content and Antioxidant Capacity}

The content of total phenolic compounds was determined by the Folin-Ciocalteu method (Singleton and Rossi 1965). In test tubes, $200 \mu \mathrm{L}$ of the aqueous fraction extracted from the film and $1000 \mu \mathrm{L}$ of the Folin-Ciocalteu reagent $(10 \%$, $\mathrm{v} / \mathrm{v})$ were mixed. Then $800 \mu \mathrm{L}$ of the sodium carbonate solution $(7.5 \%, \mathrm{wt} / \mathrm{v})$ was added and the tubes were kept in the dark for $2 \mathrm{~h}$ for reaction. A white sample was prepared by replacing the extract with distilled water. The absorbance was measured at $765 \mathrm{~nm}$ using a UV-Vis spectrophotometer (Biochrom, Libra model, Cambridge, England). A standard curve was previously prepared using different concentrations of gallic acid $(y=10.301 x-$ $\left.0.0498 ; R^{2}=0.999\right)$. The content of total phenolic compounds was expressed in $\mathrm{mg}$ equivalent gallic acid/g film.

The antioxidant capacity of the films was evaluated with the iron reduction method (FRAP) and also by the capture of the free radicals DPPH and ABTS. For the FRAP assay (Benzie and Strain 1996), an aliquot of $100 \mu \mathrm{L}$ of the extract, $300 \mu \mathrm{L}$ of distilled water, and $3.0 \mathrm{~mL}$ of the FRAP reagent (10 mM TPTZ in $40 \mathrm{mM} \mathrm{HCl}$, plus $20 \mathrm{mM}$ ferric chloride and $300 \mathrm{mM}$ acetate buffer, $\mathrm{pH} 3.6,1: 1: 10, \mathrm{v} / \mathrm{v} \mathrm{v}$ ) were added to a test tube. The tubes were shaken and kept in a water bath at $37{ }^{\circ} \mathrm{C}$ for $30 \mathrm{~min}$ for reaction. The absorbance reading $(595 \mathrm{~nm})$ was performed in a spectrophotometer (Biochrom, Libra model, Cambridge, England) and the FRAP reagent was used as a blank to calibrate the equipment. A standard Trolox curve $\left(y=0.0012 x+0.1285 ; R^{2}=0.999\right)$ was previously constructed and the results were expressed $\mu \mathrm{mol}$ Trolox/g film.

The determination of antioxidant capacity by DPPH free radical capture was done according to the method described by Mensor et al. (2001). In a test tube, an aliquot of $0.1 \mathrm{~mL}$ of the extract was mixed with $3.9 \mathrm{~mL}$ of $0.06 \mathrm{mM} \mathrm{DPPH}$ solution. After $40 \mathrm{~min}$ of reaction, the absorbance was determined in a spectrophotometer at $515 \mathrm{~nm}$. The results were calculated using a standard Trolox curve $\left(y=-0.0006 x+0.687 ; R^{2}=\right.$ 0.9987 ) and expressed in $\mu \mathrm{M}$ of Trolox equivalent per $g$ of film.

In the determination of the antioxidant capacity by the ABTS method (Thaipong et al. 2006), a stock solution of $7 \mathrm{mM}$ ABTS and $140 \mathrm{mM}$ potassium persulfate were initially prepared. To prepare the ABTS $\left(\mathrm{ABTS}^{*+}\right.$ ) radical, $5 \mathrm{~mL}$ of the stock solution of ABTS was mixed with $88 \mu \mathrm{L}$ of the potassium persulfate solution and kept in the dark at room temperature for $16 \mathrm{~h}$. Then, $1 \mathrm{~mL}$ of this mixture was diluted with ethanol until it reached an absorbance of $0.70 \pm 0.05$ at $734 \mathrm{~nm}$. In the test tubes, an aliquot of $30 \mu \mathrm{L}$ of the film extract was mixed with $3.0 \mathrm{~mL}$ of the $\mathrm{ABTS}^{\circ+}$ and the absorbance $(734 \mathrm{~nm})$ reading was performed after 6 min of reaction. The results were calculated using a standard Trolox curve $(y=$ $-0.0003 x+0.6917 ; R^{2}=0.998$ ) and expressed in $\mu \mathrm{M}$ Trolox equivalent per $\mathrm{g}$ of film.

\section{Production of Sachet-Type Packaging for Linseed Oil and Evaluation of Oxidative Stability}

The films with the highest antioxidant capacity were used to make sachet-type packaging for the storage of linseed oil. The films were cut to size $3 \times 7 \mathrm{~cm}$ and sealed. Then $5 \mathrm{~mL}$ of flaxseed oil was introduced and the opening sealed. The sachets containing oil were stored in an oven at $60^{\circ} \mathrm{C}$, according to the Schaal oven test, for 10 days (Michotte et al. 2011). The oxidative stability of the oil was monitored by determination of the peroxide index, the specific extinction coefficient, and by monitoring the ultraviolet and visible (UV-Vis) spectroscopic region.

The peroxide index was determined by iodometric titration using $0.1 \mathrm{M}$ sodium thiosulphate and starch solution as indicator (Instituto Adolfo Lutz 2008). The determination of the dienes and trienes formed during the oxidation of the oil was evaluated by UV-Vis spectroscopy (Biochrom, Libra model, Cambridge, England), in which the specific extinction coefficient $K_{232}, K_{270}$, and $\Delta K$ were obtained (Instituto Adolfo Lutz 2008). An amount of $0.25 \mathrm{~g}$ of the sample was weighed into a $25-\mathrm{mL}$ volumetric flask, dissolved and completed with cyclohexane (solution A). An aliquot of $5 \mathrm{~mL}$ from this solution was transferred and diluted to $25 \mathrm{~mL}$ of the cyclohexane in volumetric flask (solution B). The absorbance of solution A was measured in a spectrophotometer at 266, 270, and $274 \mathrm{~nm}$. By proceeding in the same manner, the absorbance of solution B was measured at $232 \mathrm{~nm}$. The specific extinction coefficient was calculated with Eqs. 2, 3, and 4.

$K_{232}=\frac{A_{232}}{c \times l}$
$K_{270}=\frac{A_{270}}{c \times l}$
$\Delta K=K_{270} \frac{A_{266}+A_{274}}{2}$

where $A_{232}, A_{266}, A_{270}$, and $A_{274}$ are the absorbance values obtained at wavelengths $232,266,270$, and $270 \mathrm{~nm}, c$ is the concentration of oil in the solution $(\mathrm{g} / 100 \mathrm{~mL})$, and $l$ is the optical path of the quartz cuvette $(1 \mathrm{~cm})$.

The UV-Vis spectra of the linseed oil in the beginning of the storage time and after 3, 7, and 10 days (for control and for extract EP2) were collected from 200 to $1100 \mathrm{~nm}$ and analyzed by multivariate curve resolution with alternating least squares (MCR-ALS) according to Gonçalves et al. (2014) by using MATLAB R2007b software. 


\section{Statistical Analysis}

The results of the film characterization were evaluated by the analysis of variance (ANOVA), and the means of the treatments were compared by Tukey's test at the $5 \%$ significance level $(p<0.05)$ using Statistica software, version 10 (Statsoft, Tulsa, OK, USA).

Data from conventional analyses of linseed oil (peroxide index, $K_{232}, K_{270}$, and $\Delta K$ ) were evaluated by principal component analysis (PCA) by using MATLAB R2007b software.

\section{Results and Discussion}

\section{Phenolic Composition of the Pinhão Coat Extract}

The peak characteristics (retention time, $\lambda_{\max }$ in the visible region, mass spectral data) determined by HPLC-DAD-ESI/ MS and tentative identification of the phenolic compounds present in the EP are shown in Table 1.

Eight phenolic compounds were identified, comprising three phenolic acids (protocatechuic acid, ferulic acid hexoside, and 3,5-O-dicaffeoylquinic acid); four flavonoid glycoside derivatives, of which three flavan-3-ols ((+)-catechin and (-)-epicatechin and B-type (epi)-catechin dimer) and one flavanone (eriodictyol-O-hexoside); and one organic acid (quinic acid). The total phenolic compound concentration in the EP was $6.42 \mathrm{mg} / \mathrm{g}$ extract, and the major compounds found were protocatechuic acid followed by catechin and Btype (epi)catechin dimer, showing that about $42 \%$ of the identified compounds were flavonoids. These results indicate that EP can be a good source of antioxidants for food packaging application. All the identified phenolic compounds were previously described by De Freitas et al. (2018) in the pinhão coat and cooking water extracts and by Santos et al. (2018) in the pinhão coat extract.

\section{Film Visual and Microstructural Properties}

The average thickness of the SPI films added with the pinhão coat extract was $150 \pm 37 \mu \mathrm{m}$, and presented good integrity, with good handling, were easily removed from the acrylic plate and there was no apparent migration of plasticizer (glycerol).

The strong brown coloration of the EP significantly affected $(p<0.05)$ the color of the films (Fig. 1, Table 2). Compared to other protein-based films, the color of pure SPI film tends to be yellowish (Han et al. 2018; Wang et al. 2016). As the concentration of EP increased, the values of $L^{*}$ and $b^{*}$ decreased and the values of $a^{*}$ increased. This, consequently, caused the $\Delta E$ values to increase as the concentration of $\mathrm{EP}$ varied. Similar color variation trends were observed in SPI films added with chestnut coat extract (Castanea molissima) (Wang et al. 2016) and starch films added with lignocellulosic fibers obtained by dry grinding of pinhão coat (Spada et al. 2018).

The incorporation of EP did not interfere in the water vapor permeability (WVP) of the SPI films, as can be observed in Table 2, possibly due to the formation of a stable network by hydrogen bonding interactions between phenolic compounds of EP and SPI functional groups (Han et al. 2018). The values of WVP were close to those found by other authors involving SPI film (Carpiné et al. 2015; Echeverría et al. 2016). With respect to the mechanical property results, it was possible to note that Young's modulus was not significantly affected $(p>0.05)$ by the addition of the EP (Table 2). However, the addition of the EP increased significantly $(p<0.05)$ both the tensile strength and the elongation at break, only when the lowest concentration of the extract was evaluated (EP0.5). De Freitas et al. (2018) also observed an increase in both tensile strength and elongation at break for zein films added from the pinhão cooking water extract. The authors concluded that the binding of phenolic compounds to zein proteins led to

Table 1 Chromatographic characterization and quantification ( $\mathrm{mg} / \mathrm{g}$ of extract) of the phenolic compounds tentatively identified in pinhão coat extract

\begin{tabular}{|c|c|c|c|c|c|c|}
\hline Peak & Rt (min) & $\lambda_{\max }(\mathrm{nm})$ & $\begin{array}{l}\text { Molecular ion } \\
{[\mathrm{M}-\mathrm{H}]^{-}(\mathrm{m} / \mathrm{z})}\end{array}$ & $\operatorname{MS}^{2}(m / z)$ & Tentative identification & $\begin{array}{l}\text { Quantification } \\
\text { (mg/g extract) }\end{array}$ \\
\hline 1 & 4.19 & 274 & 191 & $173(42), 111(100)$ & Quinic acid & $0.51 \pm 0.02$ \\
\hline 2 & 5.44 & 260,294 & 153 & $109(100)$ & Protocatechuic acid & $1.56 \pm 0.01$ \\
\hline 3 & 6.39 & 320 & 355 & $193(100)$ & Ferulic acid hexoside & $0.33 \pm 0.01$ \\
\hline 4 & 7.04 & 280 & 289 & 245 (100), 203 (11), 187 (29), 161 (14), 137 (3) & $(+)$-Catechin & $1.46 \pm 0.01$ \\
\hline 5 & 7.56 & 280 & 577 & $451(33), 425$ (100), 289 (10), 287 (3) & B-type (epi)catechin dimer & $1.23 \pm 0.05$ \\
\hline 6 & 9.66 & 279 & 289 & 245 (100), 203 (18), $187(24), 161(21), 137$ (3) & $(-)$-Epicatechin & $0.89 \pm 0.03$ \\
\hline 7 & 16.19 & $281,324 \mathrm{sh}$ & 449 & $287(100)$ & Eriodictyol- $O$-hexoside & $\operatorname{Tr}$ \\
\hline \multirow[t]{2}{*}{8} & 20.48 & 330 & 515 & 353 (23), 191 (100), 179 (51), 173 (5), 135 (4) & 3,5-O-Dicaffeoylquinic acid & $0.44 \pm 0.01$ \\
\hline & & & & & Total phenolic compounds & $6.42 \pm 0.01$ \\
\hline
\end{tabular}

$\operatorname{Tr}$ traces (compounds below LOD amounts) 


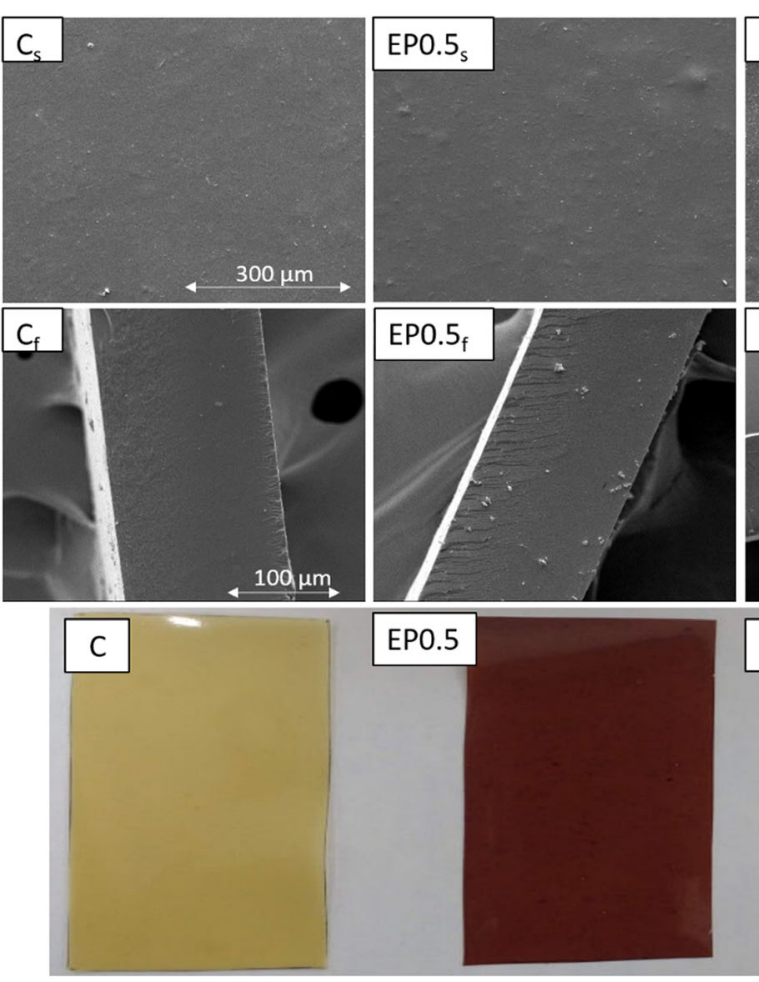

Fig. 1 SEM images of the SPI films added with pinhão coat extract (subindex " $\mathrm{s}$ " means surface images $\times 400$ magnification and " $\mathrm{f}$ " means fragile fracture images $\times 800$ magnification). Images of the produced

a decrease in the hydrophobic interactions among zein molecules. This may occur due to the action of the hydrophilic groups of the phenolic compounds that contribute to an increase in polymeric chain mobility, eliminating film brittleness. In the SPI films produced in this work, probably in the lowest concentration of EP, the phenolic compounds may be acted as crosslinking agent, improving the intramolecular interaction between SPI protein chains and reinforcing film structure that resulted in enhancement of the

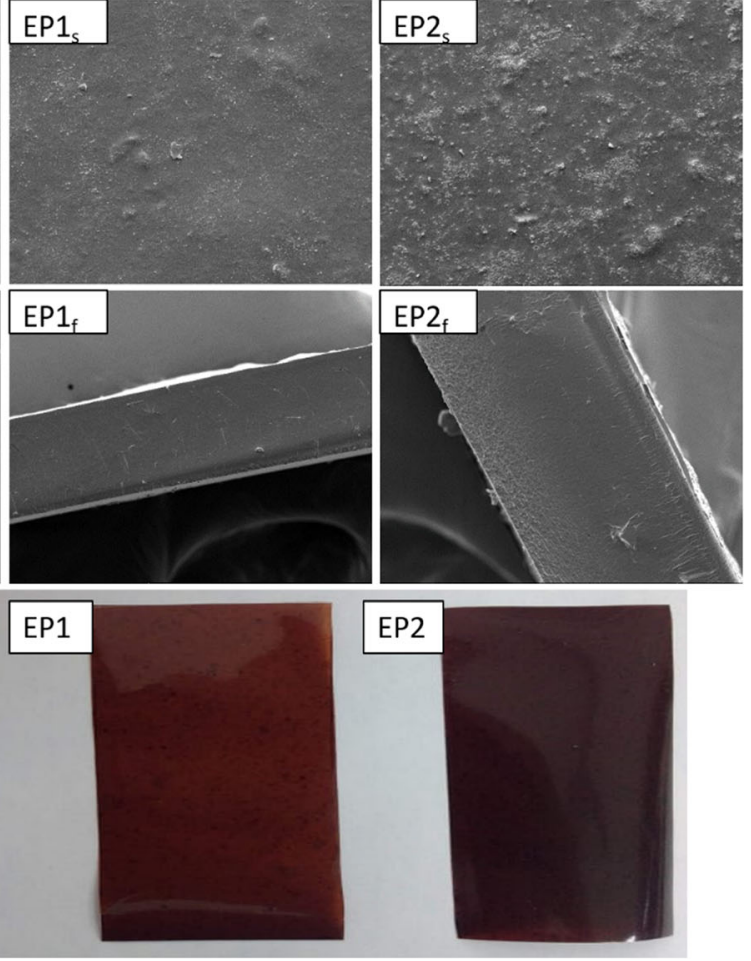

films: control (C), with $0.5 \% \mathrm{wt} / \mathrm{wt}$ of pinhão coat extract (EP0.5), $1 \%$ $\mathrm{wt} / \mathrm{wt}$ of pinhão coat extract (EP1), and $2 \% \mathrm{wt} / \mathrm{wt}$ of pinhão coat extract (EP2)

tensile strength. With the increase of EP concentration in the formulation, there was no significant difference in mechanical properties observed because the excessive concentration may impair the molecular interaction. The same behavior was also described by Wang et al. (2016) in the SPI films incorporated of chestnut bur extract.

The microstructural morphology of the films was evaluated by scanning electron microscopy (SEM) and the surface and fragile fracture images are presented in Fig. 1. In general, the

Table 2 Color measurement, mechanical properties, and water vapor permeability of the control films, with $0.5 \%$ of pinhão coat extract (EP 0.5 ), $1 \%$ of pinhão coat extract (EP 1), and $2 \%$ of pinhão coat extract (EP 2)

\begin{tabular}{|c|c|c|c|c|}
\hline \multicolumn{5}{|l|}{ Color } \\
\hline Sample & $L^{*}$ & $a^{*}$ & $b^{*}$ & $\Delta E$ \\
\hline Control & $57.33 \pm 2.85^{\mathrm{a}}$ & $0.59 \pm 0.19^{\mathrm{c}}$ & $17.54 \pm 1.63^{\mathrm{a}}$ & - \\
\hline EP0.5 & $37.08 \pm 3.66^{\mathrm{b}}$ & $17.93 \pm 1.25^{\mathrm{a}}$ & $17.37 \pm 3.03^{\mathrm{a}}$ & $26.98 \pm 2.18^{\mathrm{c}}$ \\
\hline EP1 & $31.69 \pm 3.37^{\mathrm{c}}$ & $18.35 \pm 2.92^{\mathrm{a}}$ & $12.95 \pm 4.33^{\mathrm{b}}$ & $32.01 \pm 1.91^{\mathrm{b}}$ \\
\hline EP2 & $26.52 \pm 1.30^{\mathrm{d}}$ & $13.49 \pm 2.56^{\mathrm{b}}$ & $6.26 \pm 1.71^{\mathrm{c}}$ & $35.38 \pm 0.73^{\mathrm{a}}$ \\
\hline \multicolumn{5}{|c|}{ Mechanical properties and water vapor permeability } \\
\hline Sample & Tensile strength (MPa) & Elongation at break (\%) & Young's modulus (MPa) & $\mathrm{WVP} \times 10^{10}(\mathrm{~g} / \mathrm{m} . \mathrm{s} . \mathrm{Pa})$ \\
\hline Control & $5.7 \pm 0.5^{\mathrm{a}, \mathrm{b}}$ & $148.9 \pm 22.3^{\mathrm{a}, \mathrm{b}}$ & $131.5 \pm 14.2^{\mathrm{a}}$ & $1.48 \pm 0.27^{\mathrm{a}}$ \\
\hline EP0.5 & $6.4 \pm 0.9^{\mathrm{a}}$ & $171.6 \pm 12.1^{\mathrm{a}}$ & $141.8 \pm 18.9^{\mathrm{a}}$ & $1.60 \pm 0.35^{\mathrm{a}}$ \\
\hline EP1 & $5.7 \pm 0.6^{\mathrm{a}, \mathrm{b}}$ & $136.6 \pm 25.4^{b}$ & $137.3 \pm 18.7^{\mathrm{a}}$ & $1.51 \pm 0.17^{\mathrm{a}}$ \\
\hline EP2 & $5.3 \pm 0.4^{\mathrm{b}}$ & $137.4 \pm 18.7^{\mathrm{b}}$ & $125.3 \pm 14.8^{\mathrm{a}}$ & $1.48 \pm 0.14^{\mathrm{a}}$ \\
\hline
\end{tabular}

Means followed by different superscript letters in the same column show significant difference $(p<0.05)$ according to Tukey's test WVP water vapor permeability 
films presented a smooth, homogeneous, and compact fracture, independent of the EP concentration, suggesting a good interaction between the SPI and the EP. These results corroborate with those of mechanical properties and WVP, in which no changes were observed in them due to the addition of EP. However, as the EP concentration increased in the formulation, the surface of the films tended to become more rough. This result may be associated with the behavior of the mechanical properties. The presence of the protruding points that cause the rough surface appearance of the films due to the excess of extract may have led to the formation of fragile spots in the polymer structure, which compromised the mechanical properties such as tensile strength and elongation at break.

\section{Films' FTIR-ATR and Thermal Properties}

FTIR-ATR was used to evaluate possible interactions between SPI, glycerol, and EP (Fig. 2). The spectra of the control and EP 0.5 films showed similar behavior with elongation bands of $\mathrm{OH}$ and $\mathrm{N}-\mathrm{H}$ flexion at $3270 \mathrm{~cm}^{-1}, \mathrm{C}=\mathrm{O}$ stretching at $1627 \mathrm{~cm}^{-1}$ (amide I), protein $\mathrm{N}-\mathrm{H}$ bending, and $\mathrm{C}-\mathrm{N}$ stretching at $1530 \mathrm{~cm}^{-1}$ (amide II), $\mathrm{C}-\mathrm{N}$ and $\mathrm{N}-\mathrm{H}$ vibration at $1232 \mathrm{~cm}^{-1}$ (amide $\mathrm{III}$ ), and $\mathrm{C}-\mathrm{H}$ stretching band at $2929 \mathrm{~cm}^{-1}$ (Carpiné et al. 2015; Han et al. 2018). The bands located between the 800 and $1150 \mathrm{~cm}^{-1}$ region are related to $\mathrm{C}-\mathrm{C}$ bonds $\left(850,925\right.$, and $\left.995 \mathrm{~cm}^{-1}\right)$ and $\mathrm{C}-\mathrm{O}$ (at $1045 \mathrm{~cm}^{-1}$ corresponds to the $\mathrm{C}-\mathrm{O}$ bond at $\mathrm{C} 1$ and $\mathrm{C} 3$ and at $1117 \mathrm{~cm}^{-1}$ is the $\mathrm{C}-\mathrm{O}$ bond in $\mathrm{C} 2$ ) of glycerol (Guerrero et al. 2010).

With the increase of EP concentration, it was verified that in the EP1 and EP2 spectra, there was a band enlargement at $3270 \mathrm{~cm}^{-1}$ that may be associated with $\mathrm{O}-\mathrm{H}$ vibrations of phenolic compounds present in the EP (Han et al. 2018). Some characteristic bands of SPI, such as amides I, II, and III, and glycerol became less intense and this modification can be attributed to the overlapping of functional group bands from both protein and EP. The $\mathrm{C}-\mathrm{H}$ stretching band $\left(2929 \mathrm{~cm}^{-1}\right.$ ) was shifted to $2980 \mathrm{~cm}^{-1}$. This behavior must be related to the interaction between the film and EP. In

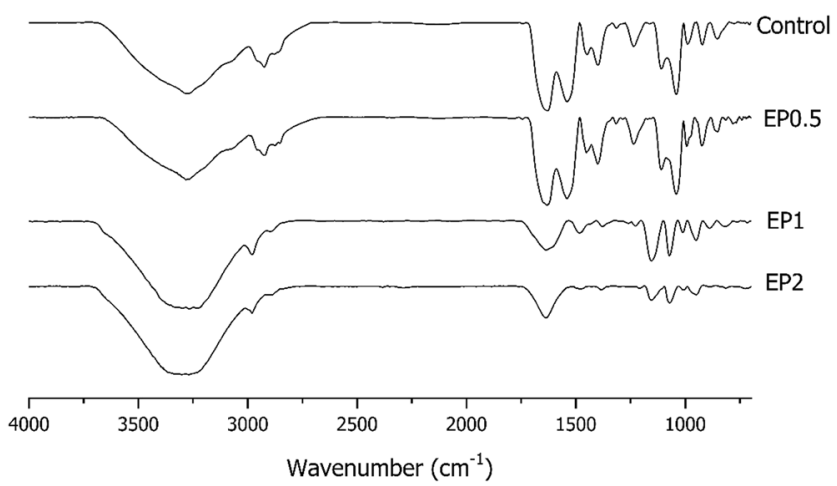

Fig. 2 FTIR-ATR spectra of the SPI films added with pinhão coat extract: control $(\mathrm{C})$, with $0.5 \% \mathrm{wt} / \mathrm{wt}$ of pinhão coat extract (EP0.5), addition, the reduction in the intensity of the characteristic bands of glycerol and a slight displacement of the bands at 1045 and $1117 \mathrm{~cm}^{-1}$ suggest interaction between glycerol and EP.

\section{Films' Phenolic Compound Content and Antioxidant Capacity}

As it can be observed in Fig. 3, for the antioxidant capacity assays tested by DPPH and FRAP, the same trend was obtained for all the samples: Control $>$ EP2 $>$ EP1 > EP0.5 $\left(\mu \mathrm{mol}\right.$ Trolox equivalent $\left./ \mathrm{g}_{\text {film }}\right)$. The significant antioxidant capacity of the control film may be related to the antioxidant action of amino acids with the phenolic side chains such as phenylalanine, tyrosine, and tryptophan, and phenolic compounds such as isoflavones and chlorogenic, caffeic, and ferulic acids present in SPI (Amigo-Benavent et al. 2008). In addition, with protein structure denaturation during film production, there was cleavage of native disulfide bonds and also exposure of sulfhydryl groups and hydrophobic groups, allowing them to react with the ABTS and DPPH radicals and to reduce the TPTZ complex, and, finally, the peptide fractions of the SPI also have antioxidant capacity (Perez-Gago et al. 1999; Wang et al. 2016).

In contrast, the addition of pinhão coat extract in the lowest proportion $(\mathrm{EP} 0.5)$ significantly reduced $(p<0.05)$ the values of all the antioxidant capacities evaluated when compared to the control film. This result is indicative of the interaction between the groups related to the antioxidant capacity of the SPI and the compounds of the pinhão coat extract, as evidenced by the FTIR-ATR spectra. It must be highlighted that there was a significant reduction in phenolic compound concentration from the control sample to EP0.5 sample, another evidence of SPI/EP interactions. Thus, there was reduction on the availability of the functional groups that could react with the ABTS and DPPH radicals and reduce the TPTZ complex, while in the EP1 and EP2 films, the remaining or excess EP was available to react with these compounds.

Comparing the different tests to determine the antioxidant capacity, it was verified that FRAP and DPPH had correlation with the total phenolic compound content, being in agreement with Thaipong et al. (2006). Relatively higher values were detected by the ABTS method when compared to the other methods, as it has a higher capacity to react with pigmented and hydrophilic antioxidants such as SPI and EP (Floegel et al. 2011). In this study, water was used to extract the phenolic compounds and antioxidants from the film. The SPI matrix is hydrophilic and swells when in contact with water and this may have facilitated the release of bioactive compounds from the matrix to solution (Han et al. 2018). 
Fig. 3 Total phenolic compound content (Folin-Ciocalteu) and antioxidant capacity evaluated by the ABTS, DPPH, and FRAP methods of the SPI films added with pinhão coat extract: control, with $0.5 \% \mathrm{wt} / \mathrm{wt}$ of pinhão coat extract (EP0.5), 1\% wt/wt of pinhão coat extract (EP1), and 2\% $\mathrm{wt} / \mathrm{wt}$ of pinhão coat extract (EP2)
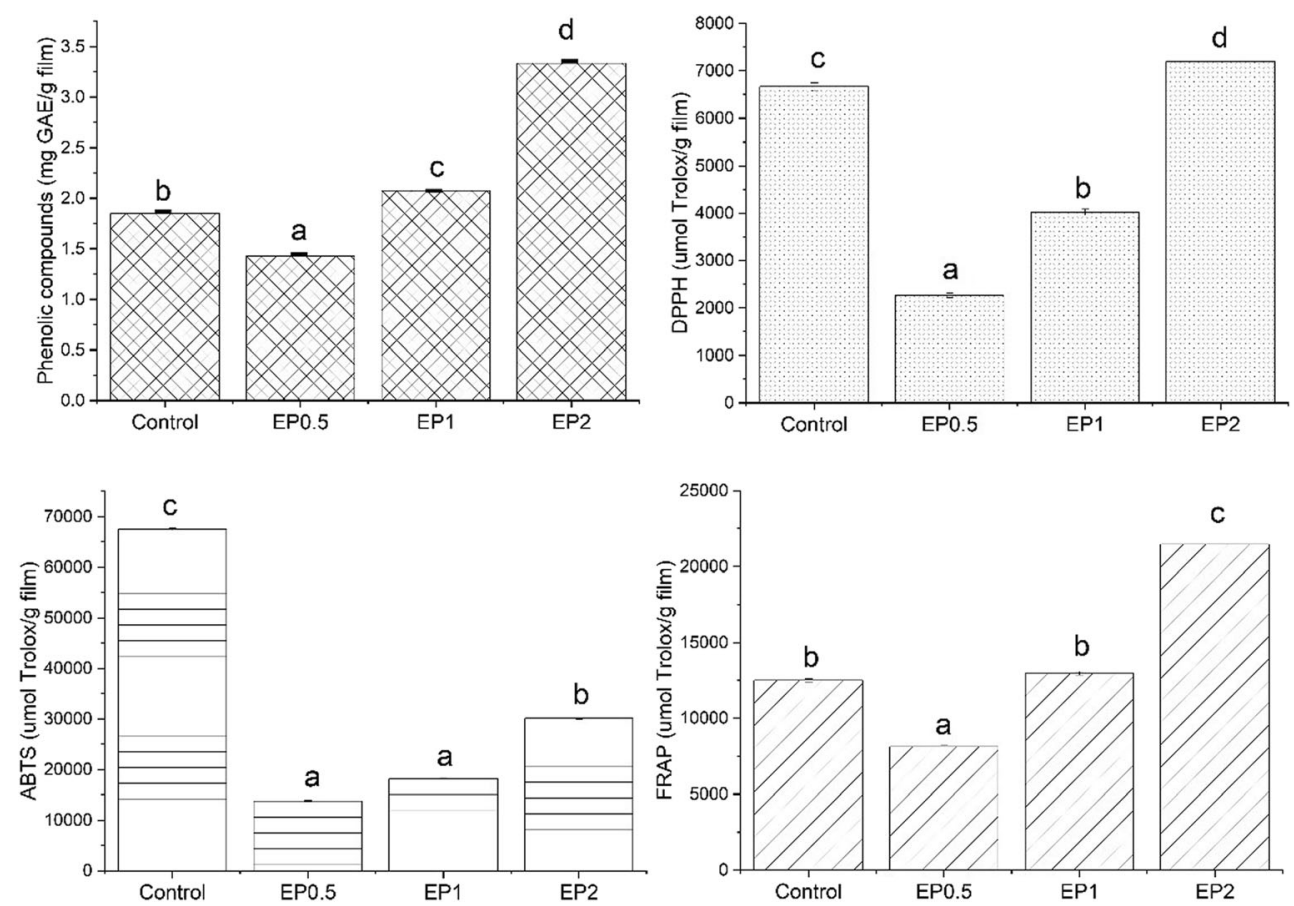

\section{Oxidative Stability of Flaxseed Oil Packed in SPI and EP Sachets}

The control and EP2 films were selected to be applied as sachet-type packaging for the linseed oil, due to their higher antioxidant capacity (Fig. 3). Shown in Fig. 4a are the UV-Vis spectra of the oil packaged with the control film, as well as with EP2 film, after 0, 3, 7, and 10 days stored at $60^{\circ} \mathrm{C}$.

Since the UV-Vis spectroscopy presents a high degree of band overlapping, as well as lack of selectivity, it is not possible to find differences between the samples only using Fig. 4a analysis. This difficulty can be overcome by using the multivariate curve resolution with alternating least squares (MCRALS) tool that can contribute to extract more information and produce reliability results. Thus, MCR-ALS was applied at the UV-Vis dataset according to Gonçalves et al. (2014), by employing a mathematical rank equal to two and restrictions of non-negativity for spectra and concentration, and concentration closure. The obtained results are presented in Fig. 4b, c.

In Fig. 4b, different spectral profiles recovered by MCRALS are shown: the spectra of tocopherol (gray line) and oxidation products (black line). Tocopherol and tocochromanols are the principal phenolic compounds present in vegetable oils. These constituents present maximum absorbance around 220 and $300 \mathrm{~nm}$, while primary and secondary oxidation compounds exhibit absorption between 220 and $234 \mathrm{~nm}$ and at $265 \mathrm{~nm}$, respectively (Vieira and RegitanoD'arce 1998). Previous research by using UV-Vis spectroscopy and MCR-ALS method applied to edible oils shows that oxidation products present absorbance between 390 and $550 \mathrm{~nm}$ (Gonçalves et al. 2014; Gonçalves et al. 2018).
Different compounds are formed in vegetable oil during storage time, while the minor components are degraded, causing rancidity and off flavors and quality and nutritional decrease (Bendini et al. 2009). These can be observed by the relative concentration profiles obtained from MCR-ALS, shown in Fig. 4c. The tocopherol concentration decreased while oxidation product concentration increased as the time was enhanced, which is in agreement with a previous study (Gonçalves et al. 2014; Gonçalves et al. 2018). One factor that can influence the storage conditions is the oxygen permeability of the packaging material (Gutiérrez-Rosales et al. 1988). To the oil packaged in the control film, the oxidation products are in higher concentration over the oil packaged in the EP2 film after 10 days of storage. The oil packaged in the EP2 film presents a lower tocopherol degradation than the control. This result can suggest a protective effect of the pinhão extract added to EP2 film.

Conventional oxidative analysis (peroxide index, $K_{270}$, $K_{232}$, and $\Delta K$ ) were done and their results are shown in Table 3. Principal component analysis (PCA), applied to Table 3 (auto scale preprocess), was made possible to graphically interpret these data. The score plot on PC1 (95.29\% of explained variance) shows the relation between samples in Fig. $4 \mathrm{~d}$. Based on score plot, it is possible to note that the oil packaged in the control film and the oil packaged in the EP2 film present similar behavior at the 3rd and 7th days of storage. However, evaluating the results obtained at the 10th day, it is possible to note that samples packaged in EP2 film are in a lower level than control samples. In order to explain the observations obtained by the scores, the loading plot (Fig. 4e) shows the importance of the variables. 

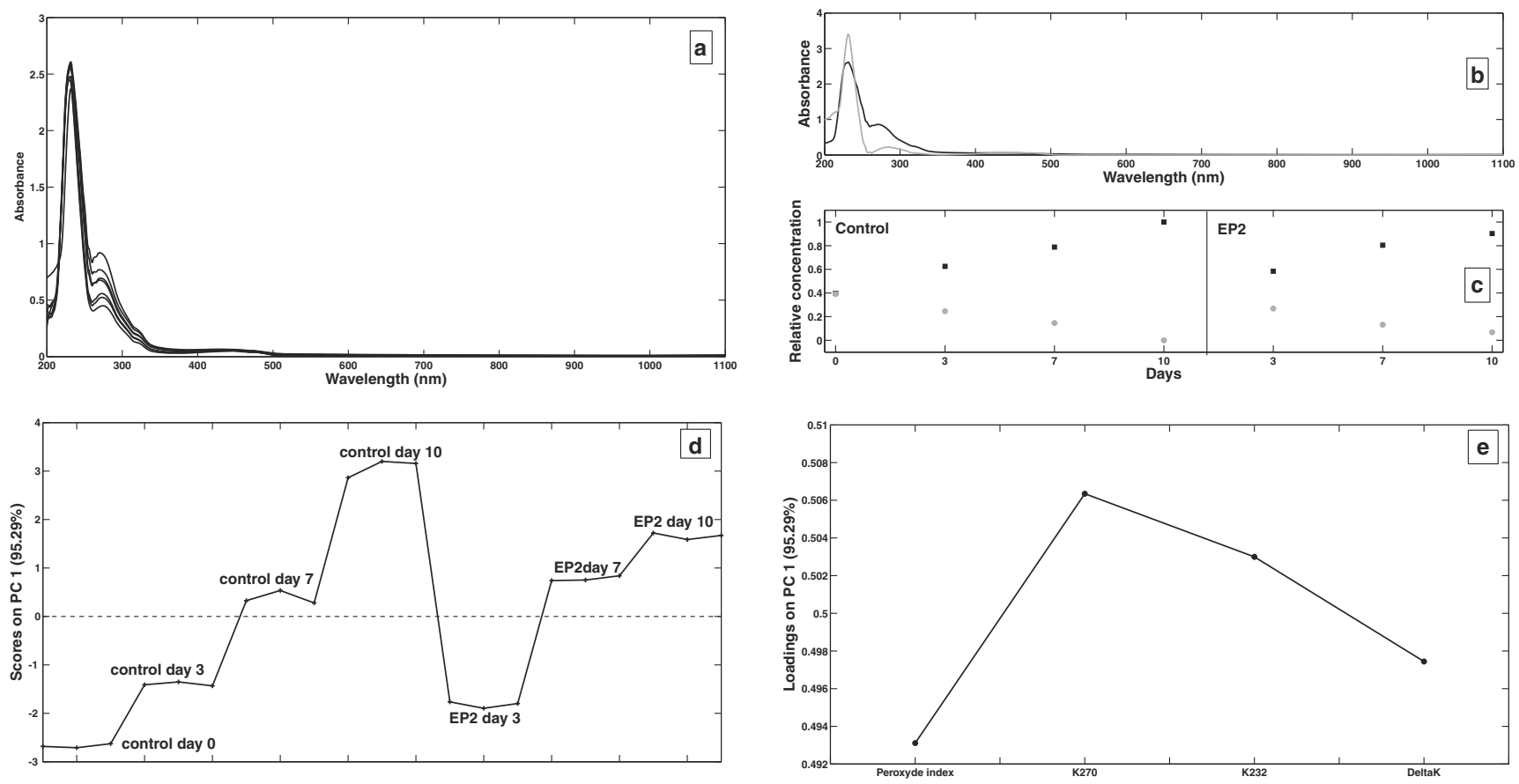

Fig. 4 a UV-Vis spectra of the oil packaged with the control film, as well as with EP2 film, after 0, 3, 7, and 10 days stored at $60^{\circ} \mathrm{C}$. MCR-ALS results: $\mathbf{b}$ recovered spectra; $\mathbf{c}$ relative concentration profiles (black $=$

oxidation products; gray $=$ tocopherol). PCA applied to the data set composed by peroxide index, $K_{270}, K_{232}$, and $\Delta K$, determined for the oil packaged on control film and EP2 film: $\mathbf{d}$ scores and $\mathbf{e}$ loading plots

By regarding the loading plot (Fig. 4e), it is possible to verify that all conventional analyses are located in the positive side from the loading plot on PC1. By visualizing the results for the 10th day in Table 3, it is possible to assign smaller values for all parameters of the conventional analysis for the oil packaged in the EP2 film. Thus, it is possible to conclude

that the addition of the extract to SPI packaging guarantees a protective effect to the oil stability.

In similar studies, Stoll et al. 2017) found a positive effect of sachets produced from cassava starch films added with anthocyanin microparticles on the oxidative stability of extra virgin olive oil. de Moraes Crizel et al. (2018) observed that gelatin

Table 3 Oxidative stability of linseed oil packed in SPI sachet-type packages (control and with $2 \% \mathrm{wt} / \mathrm{wt}$ of EP) stored at $60^{\circ} \mathrm{C}$ evaluated by peroxide indexes $K_{232}, K_{270}$, and $\Delta K$

Storage time (days)

$\begin{array}{llll}0 & 3 & 7 & 10\end{array}$

\begin{tabular}{|c|c|c|c|c|}
\hline \multicolumn{5}{|c|}{ Peroxide index } \\
\hline Control & $4.09 \pm 0.01^{\mathrm{a}}$ & $8.19 \pm 0.02^{b}$ & $17.86 \pm 2.65^{\mathrm{a}}$ & $24.56 \pm 3.55^{\mathrm{a}}$ \\
\hline EP2 & $4.09 \pm 0.01^{\mathrm{a}}$ & $5.45 \pm 1.18^{\mathrm{a}}$ & $20.44 \pm 0.05^{\mathrm{a}}$ & $23.88 \pm 1.26^{\mathrm{a}}$ \\
\hline \multicolumn{5}{|l|}{$K_{232}$} \\
\hline Control & $2.788 \pm 0.020^{\mathrm{a}}$ & $3.252 \pm 0.010^{\mathrm{b}}$ & $3.822 \pm 0.055^{\mathrm{a}}$ & $4.655 \pm 0.100^{b}$ \\
\hline EP2 & $2.788 \pm 0.020^{\mathrm{a}}$ & $3.113 \pm 0.052^{\mathrm{a}}$ & $4.195 \pm 0.074^{b}$ & $4.460 \pm 0.067^{\mathrm{a}}$ \\
\hline \multicolumn{5}{|l|}{$K_{270}$} \\
\hline Control & $0.447 \pm 0.008^{\mathrm{a}}$ & $0.565 \pm 0.008^{b}$ & $0.688 \pm 0.002^{\mathrm{a}}$ & $0.918 \pm 0.007^{\mathrm{b}}$ \\
\hline EP2 & $0.447 \pm 0.008^{\mathrm{a}}$ & $0.532 \pm 0.006^{\mathrm{a}}$ & $0.684 \pm 0.015^{\mathrm{a}}$ & $0.755 \pm 0.004^{\mathrm{a}}$ \\
\hline \multicolumn{5}{|l|}{$\Delta K$} \\
\hline Control & $0.193 \pm 0.007^{\mathrm{a}}$ & $0.311 \pm 0.009^{\mathrm{b}}$ & $0.462 \pm 0.003^{b}$ & $0.824 \pm 0.012^{\mathrm{b}}$ \\
\hline EP2 & $0.193 \pm 0.007^{\mathrm{a}}$ & $0.298 \pm 0.002^{\mathrm{a}}$ & $0.457 \pm 0.020^{\mathrm{a}}$ & $0.556 \pm 0.007^{\mathrm{a}}$ \\
\hline
\end{tabular}

Means followed by different superscript letters in the same column show significant difference $(p<0.05)$ according to Tukey's test 
film containing papaya peel microparticles was efficient as antioxidant packaging for lard. The HDPE films incorporated of marigold flower (Tagetes erecta) extract and titanium dioxide improved the oxidative stability of the soybean oil (ColínChávez et al. 2014). However, no difference was observed in the oxidative stability of extra virgin olive oil packed in sachets based on SPI films and different concentrations of coconut oil (Carpiné et al. 2015), confirming that SPI films enriched with pinhão extract developed in this work were more efficient to maintain the oxidative stability of the oil.

\section{Conclusion}

The EP, obtained from the cooking water of the pinhão seeds, is a rich source of phenolic compounds, that when added to the SPI film formulation did not cause significant changes in the mechanical properties (above 1\% wt) and WVP. As evidenced in the FTIR-ATR spectra, a higher interaction between the EP and SPI occurred at the concentration of $0.5 \% \mathrm{wt} / \mathrm{wt}$ of extract in the film. In addition, the EP provided antioxidant capacity to the films, dark brown coloration, and contributed to the oxidative stability of flaxseed oil and is therefore an alternative to be used as active biodegradable packaging.

Acknowledgments The authors thank the Multiuser Laboratory of Federal University - Paraná - Campus Londrina, Bremil company, for the donation of SPI.

Funding Information The authors thank the $\mathrm{CNPq}$ for the financial support (project no. 420055 / 2018-5) and scholarship. This study was financed in part by the Coordenação de Aperfeiçoamento de Pessoal de Nível Superior - Brasil (CAPES) - Finance Code 001 (Masters Scholarships). The authors are also grateful to the Foundation for Science and Technology (FCT, Portugal) and FEDER under Programme PT2020 for financial support to CIMO (UID/AGR/00690/ 2019); national funding by FCT, P.I., through the institutional scientific employment program-contract for M.I. Dias and L. Barros contracts; and to FEDER-Interreg España-Portugal program for financial support through the project 0377_Iberphenol_6_E.

\section{References}

Amigo-Benavent, M., Silván, J. M., Moreno, F. J., Villamiel, M., \& Del Castillo, M. D. (2008). Protein quality, antigenicity, and antioxidant activity of soy-based foodstuffs. Journal of Agricultural and Food Chemistry, 56(15), 6498-6505. https://doi.org/10.1021/jf800697n.

Bendini, A., Cerretani, L., Salvador, M. D., Fregapane, G., \& Lercker, G. (2009). Stability of the sensory quality of virgin olive oil during storage: an overview. Italian Journal of Food Science, 21(4), 389406.

Benzie, I. F. F., \& Strain, J. J. (1996). The ferric reducing ability of plasma (FRAP) as a measure of "antioxidant power": the FRAP assay. Analytical Biochemistry, 239(1), 70-76. https://doi.org/10. 1006/abio.1996.0292.

Bessada, S. M. F., Barreira, J. C. M., Barros, L., Ferreira, I. C. F. R., \& Oliveira, M. B. P. P. (2016). Phenolic profile and antioxidant activity of Coleostephus myconis (L.) Rchb.f.: an underexploited and highly disseminated species. Industrial Crops and Products, 89, 45-51. https://doi.org/10.1016/j.indcrop.2016.04.065.

Bozan, B., \& Temelli, F. (2008). Chemical composition and oxidative stability of flax, safflower and poppy seed and seed oils. Bioresource Technology, 99(14), 6354-6359. https://doi.org/10. 1016/j.biortech.2007.12.009.

Cao, N., Fu, Y., \& He, J. (2007). Preparation and physical properties of soy protein isolate and gelatin composite films. Food Hydrocolloids, 21(7), 1153-1162. https://doi.org/10.1016/j.foodhyd.2006.09.001.

Carpiné, D., Dagostin, J. L. A., Bertan, L. C., \& Mafra, M. R. (2015). Development and characterization of soy protein isolate emulsionbased edible films with added coconut oil for olive oil packaging: barrier, mechanical, and thermal properties. Food and Bioprocess Technology, 8(8), 1811-1823. https://doi.org/10.1007/s11947-0151538-4.

Choe, E., \& Min, D. B. (2006). Mechanisms and factors for edible oil oxidation. Comprehensive Reviews in Food Science and Food Safety, 5(4), 169-186. https://doi.org/10.1111/j.1541-4337.2006. 00009.x.

Ciannamea, E. M., Stefani, P. M., \& Ruseckaite, R. A. (2016). Properties and antioxidant activity of soy protein concentrate films incorporated with red grape extract processed by casting and compression molding. $L W T, 74$, 353-362. https://doi.org/10.1016/j.lwt.2016.07. 073.

Colín-Chávez, C., Vicente-Ramírez, E. B., Soto-Valdez, H., Peralta, E., \& Auras, R. (2014). The release of carotenoids from a lightprotected antioxidant active packaging designed to improve the stability of soybean oil. Food and Bioprocess Technology, 7(12), 3504-3515. https://doi.org/10.1007/s11947-014-1359-x.

Cordenunsi, B. R., Wenzel de Menezes, E., Genovese, M. I., Colli, C., Gonçalves de Souza, A., \& Lajolo, F. M. (2004). Chemical composition and glycemic index of Brazilian pine (Araucaria angustifolia) seeds. Journal of Agricultural and Food Chemistry, 52(11), 34123416. https://doi.org/10.1021/jf0348141.

De Freitas, T. B., Santos, C. H. K., da Silva, M. V., Shirai, M. A., Dias, M. I., Barros, L., et al. (2018). Antioxidants extraction from Pinhão (Araucaria angustifolia (Bertol.) Kuntze) coats and application to zein films. Food Packaging and Shelf Life, 15(2017), 28-34. https://doi.org/10.1016/j.fpsl.2017.10.006.

de Moraes Crizel, T., Rios, A. O., Alves, V. D., Bandarra, N., MoldãoMartins, M., \& Flôres, S. H. (2018). Biodegradable films based on gelatin and papaya peel microparticles with antioxidant properties. Food and Bioprocess Technology, 11(3), 536-550. https://doi.org/ 10.1007/s11947-017-2030-0.

Echeverría, I., López-Caballero, M. E., Gómez-Guillén, M. C., Mauri, A. N., \& Montero, M. P. (2016). Structure, functionality, and active release of nanoclay-soy protein films affected by clove essential oil. Food and Bioprocess Technology, 9(11), 1937-1950. https://doi. org/10.1007/s11947-016-1777-z.

Floegel, A., Kim, D. O., Chung, S. J., Koo, S. I., \& Chun, O. K. (2011). Comparison of ABTS/DPPH assays to measure antioxidant capacity in popular antioxidant-rich US foods. Journal of Food Composition and Analysis, 24(7), 1043-1048. https://doi.org/10.1016/j.jfca. 2011.01.008.

Friesen, K., Chang, C., \& Nickerson, M. (2015). Incorporation of phenolic compounds, rutin and epicatechin, into soy protein isolate films: mechanical, barrier and cross-linking properties. Food Chemistry, 172, 18-23. https://doi.org/10.1016/j.foodchem.2014.08.128.

Gonçalves, R. P., Março, P. H., \& Valderrama, P. (2014). Thermal edible oil evaluation by UV-Vis spectroscopy and chemometrics. Food Chemistry, 163, 83-86. https://doi.org/10.1016/j.foodchem.2014. 04.109.

Gonçalves, T. R., Rosa, L. N., Gonçalves, R. P., Torquato, A. S., Março, P. H., Marques Gomes, S. T., Matsushita, M., \& Valderrama, P. (2018). Monitoring the oxidative stability of monovarietal extra 
virgin olive oils by UV-Vis spectroscopy and MCR-ALS. Food Analytical Methods, 11(7), 1936-1943. https://doi.org/10.1007/ s12161-018-1149-6.

Guerrero, P., Retegi, A., Gabilondo, N., \& De La Caba, K. (2010). Mechanical and thermal properties of soy protein films processed by casting and compression. Journal of Food Engineering, 100(1), 145-151. https://doi.org/10.1016/j.jfoodeng.2010.03.039.

Gutiérrez-Rosales, F., Gómez-Herrera, C., \& Gutiérrez-GonzálezQuijano, R. (1988). Estudios de la cinética de evolución de los índices de calidad del aceite de olive virgin durante su conservacíon en envases comerciales. Grasas y Aceites, 39, 245 253.

Han, Y., Yu, M., \& Wang, L. (2018). Preparation and characterization of antioxidant soy protein isolate films incorporating licorice residue extract. Food Hydrocolloids, 75, 13-21. https://doi.org/10.1016/j. foodhyd.2017.09.020.

Insaward, A., Duangmal, K., \& Mahawanich, T. (2015). Mechanical, optical, and barrier properties of soy protein film as affected by phenolic acid addition. Journal of Agricultural and Food Chemistry, 63(43), 9421-9426. https://doi.org/10.1021/j5504016m.

Instituto Adolfo Lutz. (2008). Metodos físico-químicos para analise de alimentos. Metodos Físico-Químicos para An alise de Alimentos.

Kumar, P., Sandeep, K. P., Alavi, S., Truong, V. D., \& Gorga, R. E. (2010). Effect of type and content of modified montmorillonite on the structure and properties of bio-nanocomposite films based on soy protein isolate and montmorillonite. Journal of Food Science, 75(5), N46-N56. https://doi.org/10.1111/j.1750-3841.2010.01633. $\mathrm{x}$.

Maryam Adilah, Z. A., Jamilah, B., \& Nur Hanani, Z. A. (2018). Functional and antioxidant properties of protein-based films incorporated with mango kernel extract for active packaging. Food Hydrocolloids, 74, 207-218. https://doi.org/10.1016/j.foodhyd. 2017.08.017.

Mensor, L. L., Menezes, F. S., Leitão, G. G., Reis, A. S., Santos, T. C., Coube, C. S., et al. (2001). Screening of Brazilian plant extracts for antioxidant activity by the use of DPPH free radical method. Phytotherapy Research, 15(2), 127-130.

Michotte, D., Rogez, H., Chirinos, R., Mignolet, E., Campos, D., \& Larondelle, Y. (2011). Linseed oil stabilisation with pure natural phenolic compounds. Food Chemistry, 129(3), 1228-1231. https:// doi.org/10.1016/j.foodchem.2011.05.108.

Mohanan, A., Nickerson, M. T., \& Ghosh, S. (2018). Oxidative stability of flaxseed oil: effect of hydrophilic, hydrophobic and intermediate polarity antioxidants. Food Chemistry, 266, 524-533. https://doi. org/10.1016/j.foodchem.2018.05.117.

Neltner, T. G., Alger, H. M., Leonard, J. E., \& Maffini, M. V. (2013). Data gaps in toxicity testing of chemicals allowed in food in the United States. Reproductive Toxicology, 42, 85-94. https://doi.org/ 10.1016/j.reprotox.2013.07.023.

Paglione, I. S., Galindo, M. V., Souza, K. C., Yamashita, F., Sakanaka, L. S., Grosso, C. R. F., et al. (2019). Optimization of the conditions for producing soy protein isolate films. Emirates Journal of Food and
Agriculture, 31(4), 297. https://doi.org/10.9755/ejfa.2019.v31.i4. 1933.

Perez-Gago, M. B., Nadaud, P., \& Krochta, J. M. (1999). Water vapor permeability, solubility, and tensile properties of heat-denatured versus native whey protein films. Journal of Food Science, 64(6), 1034-1037. https://doi.org/10.1111/j.1365-2621.1999.tb12276.x.

Salgado, P. R., Ortiz, C. M., Musso, Y. S., Di Giorgio, L., \& Mauri, A. N. (2015). Edible films and coatings containing bioactives. Current Opinion in Food Science, 5, 86-92. https://doi.org/10.1016/j.cofs. 2015.09.004.

Santos, C. H. K., Baqueta, M. R., Coqueiro, A., Dias, M. I., Barros, L., Barreiro, M. F., Ferreira, I. C. F. R., Gonçalves, O. H., Bona, E., da Silva, M. V., \& Leimann, F. V. (2018). Systematic study on the extraction of antioxidants from pinhão (Araucaria angustifolia (Bertol.) Kuntze) coat. Food Chemistry, 261(April), 216-223. https://doi.org/10.1016/j.foodchem.2018.04.057.

Singleton, V. L., \& Rossi, J. A. (1965). Colorimetry of total phenolics with phosphomolybdic-phosphotungstic acid reagents. American Journal of Enology and Viticulture, 16(3), 144 LP-144158 http:// www.ajevonline.org/content/16/3/144.abstract.

Siripatrawan, U., \& Noipha, S. (2012). Active film from chitosan incorporating green tea extract for shelf life extension of pork sausages. Food Hydrocolloids, 27(1), 102-108. https://doi.org/10.1016/j. foodhyd.2011.08.011.

Spada, J. C., Luchese, C. L., \& Tessaro, I. C. (2018). Potential of pinhão coat as constituents of starch based films using modification techniques. Journal of Polymers and the Environment, 26(7), 26862697. https://doi.org/10.1007/s10924-017-1158-3.

Stoll, L., Silva, A. M., Iahnke, A. O. S., Costa, T. M. H., Flôres, S. H., \& Rios, A. d. O. (2017). Active biodegradable film with encapsulated anthocyanins: effect on the quality attributes of extra-virgin olive oil during storage. Journal of Food Processing and Preservation, 41(6), e13218. https://doi.org/10.1111/jfpp.13218.

Thaipong, K., Boonprakob, U., Crosby, K., Cisneros-Zevallos, L., \& Hawkins Byrne, D. (2006). Comparison of ABTS, DPPH, FRAP, and ORAC assays for estimating antioxidant activity from guava fruit extracts. Journal of Food Composition and Analysis, 19(6-7), 669-675. https://doi.org/10.1016/j.jfca.2006.01.003.

Vieira, T. M. F. S., \& Regitano-D'arce, M. A. B. (1998). Stability of oils heated by microwave: UV-spectrophotometric evaluation. Ciência e Tecnologia de Alimentos, 18(4), 433-437. https://doi.org/10.1590/ S0101-20611998000400015.

Wang, H., Hu, D., Ma, Q., \& Wang, L. (2016). Physical and antioxidant properties of flexible soy protein isolate films by incorporating chestnut (Castanea mollissima) bur extracts. LWT - Food Science and Technology, 71, 33-39. https://doi.org/10.1016/j.lwt.2016.03. 025.

Publisher's Note Springer Nature remains neutral with regard to jurisdictional claims in published maps and institutional affiliations. 